\title{
Malign ile benign portal ven trombozunun ayrımında 3 Tesla manyetik rezonans görüntülemede difüzyon ağırlıklı görüntülemenin rolü
}

\author{
The use of diffusion-weighted imaging at 3 Tesla magnetic resonance imaging in differentiating \\ malignant from benign portal vein thrombosis
}

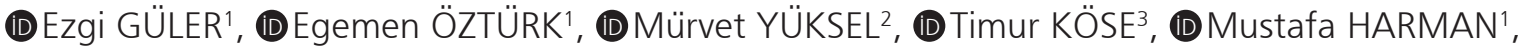 \\ (D) Ahmet Ömer ÖZÜTEMIZ4, (D) Nevra Zehra ELMAS`
}

Ege Üniversitesi Tıp Fakültesi, ${ }^{1}$ Radyoloji Anabilim Dalı, ${ }^{3}$ Biyoistatistik Anabilim Dalı, ${ }^{4}$ Gastroenteroloji Bilim Dalı, İzmir

Kahramanmaraş Sütçü İmam Üniversitesi Tıp Fakültesi ²Radyoloji Anabilim Dalı, Kahramanmaraş

\begin{abstract}
Giriş ve Amaç: Bu çalışmada malign ile benign portal ven trombozunun ayrımında 3 Tesla manyetik rezonans görüntülemede difüzyon ağırIıklı görüntülemenin rolünün araştırılması amaçlanmaktadır. Gereç ve Yöntem: Ocak 2011 - Aralık 2016 tarihleri arasında 3 Tesla manyetik rezonans görüntüleme ünitesinde elde edilmiş abdomen manyetik rezonans görüntüleme incelemeleri portal ven trombozu mevcut olguları tespit etmek için retrospektif olarak değerlendirildi. Kontrastsız görüntüler ile karşılaştırılığında arteriyel faz kontrastlı görüntülerde $\geq \% 15$ kontrast tutulumu gösteren portal ven trombozu malign olarak kabul edildi. Tromboz saptanan portal venin çapı ölçülüp difüzyon ağırlıkı görüntülerde portal ven trombozu sinyal intensitesi kaydedildi. iki bağımsız gözlemci tarafından malign ve benign portal ven trombozlarının görünür difüzyon katsayısı değerleri ölçüldü. Bulgular: Malign portal ven trombozu bulgusu olan 23 olgu [19 erkek, 4 kadın; ortanca yaş 63 (52-83)] ve benign portal ven trombozu bulgusu olan 14 olgu [5 erkek, 9 kadın; ortanca yaş 65 (47-82)] tespit edildi. Difüzyon ağırlıklı görüntülerde malign ile benign portal ven trombozu sinyal intensitesi yönünden istatistiksel olarak anlamlı fark saptandı $(p<0.05)$. Malign portal ven trombozu ortalama görünür difüzyon katsayısı değerleri benign portal ven trombozundan daha düşük saptandı $(p<0.05)$. Görünür difüzyon katsayısı değerleri ölçümü göz önüne alındığında iki gözlemci arasında güvenirlik yüksek olarak tespit edildi ( $R_{1}:$ 0.948). Görünür difüzyon katsayısı değeri $\leq 1.4 \times 10^{-3} \mathrm{~mm}^{2} / \mathrm{s}$ olduğunda malign portal ven trombozu tanısında duyarlıık ve özgüllük \%100 olarak saptandı. Sonuç: 3 Tesla manyetik rezonans görüntülemede difüzyon ağırlıklı görüntüler malign ile benign portal ven trombozu ayrımında tanıya katkı sağlamaktadır. Portal ven trombozunun difüzyon ağırlıkı görüntülerdeki sinyal intensitesi ve görünür difüzyon katsayısı değerleri ile karakterizasyonunun yapılabilmesi özellikle kontrast madde kullanımının uygun olmadığı olgularda önem taşımaktadır.
\end{abstract}

Anahtar kelimeler: Portal ven, tromboz, manyetik rezonans görüntüleme, difüzyon ağırlıkı manyetik rezonans görüntüleme

\section{GíRiş}

Portal ven trombozu (PVT) siroz, malignite, enfeksiyon, inflamatuvar hastalıklar, myeloproliferatif hastalıklar, hiperkoagülasyon durumları gibi çeşitli nedenlerden kaynaklanmaktadır (1-4). Neoplastik hastalıklarda gelişen

İletişim: Ezgi GÜLER

Ege Üniversitesi Tıp Fakültesi Radyoloji Anabilim Dalı, Bornova, İmir

Faks: +902323420001

E-mail: gulerezgi@yahoo.com
Background and Aims: The purpose of this study was to evaluate the use of diffusion-weighted imaging at 3 Tesla magnetic resonance imaging in differentiating malignant from benign portal vein thrombosis. Materials and Method: Abdominal magnetic resonance imaging examinations obtained at 3 Tesla magnetic resonance imaging unit between January 2011 and December 2016 were reviewed retrospectively to identify the cases with portal vein thrombosis. Portal vein thrombosis was considered malignant if it enhanced $\geq 15 \%$ on arterial phase contrast-enhanced images relative to precontrast images. Moreover, the diameter of the portal vein involved with the thrombus was measured, and the signal intensity of the portal vein thrombosis on diffusion-weighted images was recorded. The apparent diffusion coefficient values for malignant and benign portal vein thrombosis were calculated by two independent readers. Results: In this study, 23 patients with malignant portal vein thrombosis [19 men, 4 women; median age 63 years (52-83)] and 14 patients with benign portal vein thrombosis (5 men, 9 women; median age 65 years 47-82)] were identified. Statistically significant difference was observed in signal intensity on diffusion-weighted images $(p<0.05)$ between malignant and benign portal vein thrombosis. The mean apparent diffusion coefficient values for malignant portal vein thrombosis were significantly lower than those for benign portal vein thrombosis $(p<0.05)$. Furthermore, there was a high agreement on the calculation of apparent diffusion coefficient values $\left(R_{1}\right.$ : 0.948) between the two readers. Sensitivity and specificity values were both $100 \%$ for the diagnosis of malignant portal vein thrombosis when the apparent diffusion coefficient value was $\leq 1.4 \mathrm{x}$ $10^{-3} \mathrm{~mm}^{2} / \mathrm{s}$. Conclusion: Thus, diffusion-weighted imaging at 3 Tesla magnetic resonance imaging is beneficial for the differentiation of malignant and benign portal vein thrombosis. Characterization of portal vein thrombosis using its signal intensity on diffusion-weighted images and apparent diffusion coefficient values is important in patients in whom the use of contrast media is contraindicated.

Key words: Portal vein, thrombosis, magnetic resonance imaging, diffusion-weighted imaging

malign PVT tedaviyi ve prognozu etkileyen önemli bir faktördür (5-7). Malign PVT hepatosellüler kanser (HSK) tanılı olguların \%6.5-\%44'ünde saptanmaktadır (8). Malign PVT varlığında karaciğer transplantasyonu kontrendi- 
ke olup hastalık genellikle kötü prognoz göstermektedir $(5,6)$. Benign PVT ise siroz nedeniyle takipli olgularda sık görülmekte olup prevalansı \%0.6-\%26 olarak bildirilmiştir $(9,10)$. Hepatosellüler kanser olgularında benign PVT gelişebilmekte, malignite nedeniyle takipli olgularda benign ve malign PVT birlikte de görülebilmektedir $(5,11)$. Bu nedenle malign ile benign PVT ayrımının yapılması tedavinin yönlendirilmesi için büyük önem taşımaktadır.

Portal ven trombozunun karakterizasyonunda altın standart histopatolojik inceleme olmakla birlikte portal ven örneklemesinin taşıdığı riskler ve olası tanısal zorluklar nedeniyle klinik uygulamada PVT ayrımı sıklıkla radyolojik ve klinik bulguların birlikte değerlendirilmesi ile yapılmaktadır $(12,13)$. Benign PVT genellikle siroz olgularında yavaşlamış kan akımına bağlı gelişsirken, malign PVT tümörün portal ven dalına invazyonu sonucu gelişir. Malign PVT tümör neovasküleritesi ile ilişkili olup bu bulgu kontrastlı bilgisayarlı tomografi (BT) veya manyetik rezonans görüntüleme (MRG) incelemesinde trombozda kontrastlanma artışı olarak saptanmaktadır (14-16). Ayrıca malign ve benign PVT ayrımında damar çapının önemli olduğu, malign PVT olgularında damar çapının daha geniş ölçüldüğü bildirilmiştir $(15,16)$. Manyetik rezonans görüntüleme incelemelerinde difüzyon ağırlıkı görüntüleme (DAG) son yıllarda sıklıkla kullanılmaktadır. Su moleküllerinin farklı dokulardaki Brownian hareketi farklıı̆ı temeline dayanan DAG kullanımı ile benign karaciğer lezyonlarının malign lezyonlardan ayrımının yapılabileceği bildirilmiştir (1722). Difüzyon ağırlıklı görüntülemenin malign ve benign PVT ayrımında tanıya katkı sağlayabileceği de bildirilmiştir $(8,23)$. Ancak literatürde 3 Tesla (T) MRG ile DAG'nin PVT karakterizasyonundaki kullanımını bildiren araştırmalar kısıtllık göstermektedir.

Bu çalışma ile malign PVT ve benign PVT ayrımında $3 T$ MRG ile DAG'nin rolünün araştııılması amaçlanmaktadır.

\section{GEREÇ ve YÖNTEM}

\section{Çalışma Popülasyonu}

Ocak 2011- Aralık 2016 tarihleri arasında Ege Üniversitesi Tıp Fakültesi Hastanesi Radyoloji Bölümü'müzde 3T MRG ile elde edilmiş DAG içeren abdomen MRG incelemeleri PVT mevcut olguların tespit edilmesi için retrospektif olarak değerlendirildi. Çalışmaya dahil edilme kriterleri; erişkin hastalar ( $\geq 18$ yaş), 3T MRG ile elde edilmiş ve DAG içeren abdomen MRG incelemesi olan hastalar olarak belirlendi. Çalışmadan dışlanma kriterleri ise; 3T MRG ile elde edilmiş ancak DAG içermeyen abdomen MRG incelemesi olan hastalar, 1.5T MRG ile elde edilmiş DAG içeren abdomen MRG incelemesi olan hastalar, 3T MRG ile elde edilmiş ancak artefaktlar nedeniyle DAG değerlendirilmesi uygun olmayan hastalar, radyolojik olarak kronik PVT bulgusu olan hastalar olarak saptandı.

Olguların demografik bilgileri ve klinik tanıları elektronik hasta dosyalarından araştırılarak kaydedildi.

\section{Manyetik Rezonans Görüntüleme Tekniği ve Görüntü Analizi}

Abdomen MRG incelemeleri 3T MRG ünitesi (Magnetom Verio, Siemens, Almanya) kullanılarak elde edildi. Üst abdomen MRG protokolünde T1-ağırlıkı in-phase ve out-of-phase görüntüler [tekrarlama zamanı (TR) ms/eko zamanı (TE) ms, 150/2.46-6.15; kesit kalınlığı: 6 mm], koronal yarı Fourier kazanımlı tek atımlı turbo spin eko [half-Fourier acquisition single-shot turbo spin-echo (HASTE)] görüntüler (TR: 1200 ms, TE: 93 ms; kesit kalınlığı: 5 mm), aksiyel HASTE görüntüler (TR: 1200 ms, TE: 95 ms; kesit kalınlığı: $6 \mathrm{~mm}$ ), aksiyel turbo spin-eko T2-ağırlıklı yağ baskılı görüntüler (TR: 2500 ms, TE: 110 ms; kesit kalınlığı: $6 \mathrm{~mm}$ ) alındı. Aksiyel eko-planar DAG sekansı (b değeri: 50, 400 ve 800 s/mm²) (TR: 6400 ms, TE: 72 ms; kesit kalınlığı: $6 \mathrm{~mm}$ ) elde edildi. DAG sekansından otomatik olarak görüntü konsolunda görünür difüzyon katsayısı [apparent diffusion coefficient (ADC)] haritası oluşturuldu. Prekontrast aksiyel T1-ağırlıkı yağ baskııı volümetrik ara değerli soluk tutmalı inceleme [volumetric interpolated breath-hold (VIBE)] sekansının alınmasını takiben intravenöz yolla otomatik enjektör aracılığıyla 0.1 $\mathrm{ml} / \mathrm{kg}$ gadolinyumlu kontrast madde verilerek kontrastlı dinamik T1-ağırlıklı yağ baskılı görüntüler elde edildi. Dinamik kontrastlı görüntüler kontrast madde enjeksiyonunu takiben arteriyel faz, portal venöz faz ve geç fazda elde edildi.

Portal venöz trombozu tanısı, portal venöz faz kontrast॥ T1-ağırlıklı görüntülerde damar lümenini parsiyel veya tam olarak oklüde eden dolum defektlerinin saptanmasıyla kondu. Abdominal radyoloji alanında uzman iki radyolog MRG incelemelerini değerlendirerek olguları malign ve benign PVT olarak iki gruba ayırdı. Malign ve benign PVT ayrımında Shah ve ark.nın tanımladığı kontrastlanma kriteri göz önüne alındı (24). Prekontrast görüntüler ile karşılaştırılığında arteriyel faz kontrastı görüntülerde $\geq \% 15$ kontrast tutulumu gösteren PVT malign olarak kabul edildi. İki radyoloğun ortak değerlendirmesi ile PVT lokalizasyonu (ana portal ven, sağ ve sol portal ven dalları) kaydedildi. Portal ven trombozu olan damar lümeninin çapı ölçüldü. Difüzyon ağırlıklı görüntülerde PVT sinyal intensitesi (izointens, hipointens veya hiperintens) değerlendirildi. Bu iki radyologdan farklı abdominal radyoloji alanında uzman bir radyolog ile bir radyoloji asistanı tara- 
fından DAG sekansından elde edilmiş ADC haritalarından PVT ADC değerleri ayrı ayrı ölçüldü. ADC görüntülerinde, PVT alanının yaklaşık üçte ikisini kapsayacak ancak PVT dışında kalan alanı içermeyecek şekilde region of interest (ROI) yerleştirilerek ADC değerlerinin ölçümü yapıldı.

\section{İstatistiksel Analiz}

Istatistiksel analiz Windows için IBM SPSS Statistics, versiyon 22.0. (IBM Corp. Armonk, NY) kullanılarak yapıldı. Normal dağılım gösteren sürekli değişkenler ortalama \pm standart sapma, normal dağııım göstermeyen sürekli değişkenler ise ortanca (minimum-maksimum) hesaplanarak belirtildi. Difüzyon ağırlıklı görüntülerde benign ve malign PVT sinyal intensitesi yönünden yapılan karşılaştırmalarda Pearson ki-kare, Fisher's exact ve Mann-Whitney $U$ testleri kullanıldı. Benign ve malign PVT gruplarında ADC değerleri yönünden yapılan incelemede bağımsız örneklemler için t-testi kullanıldı. $p$ değeri $<0.05$ istatistiksel olarak anlamlı kabul edildi. Benign ve malign PVT ayrımı için eşik ADC değerinin saptanması amacıyla alıcı çalışma karakteristiği [receiver operating characteristic (ROC)] analizi yapıldı. Portal ven trombozu ADC değerlerinin ölçümünde radyologlar arasındaki güvenirlik sınıf içi korelasyon ile değerlendirildi. Sınıf içi korelasyon katsayısı $\left[\mathrm{R}_{1}-(\mathrm{ICC})\right]$ : 0.70-0.84 orta, $\mathrm{R}_{1}$-(ICC): 0.85-0.94 yüksek, $\mathrm{R}_{1}$-(ICC): 0.951.00 mükemmel güvenirlik olarak kabul edildi.

Bu retrospektif araştırma için Ege Üniversitesi Tıp Fakültesi Klinik Araştırma Etik Kurulu'ndan onay alındı (karar no: 17-12/28).

\section{BULGULAR}

\section{Olgular}

Abdomen MRG incelemelerinde PVT saptanan toplam 44 olgunun tetkiki 3T MRG ünitesinde yapılmış ve DAG içermekteydi. 3T MRG ünitesinde tetkiki yapılmış 7 olgu DAG

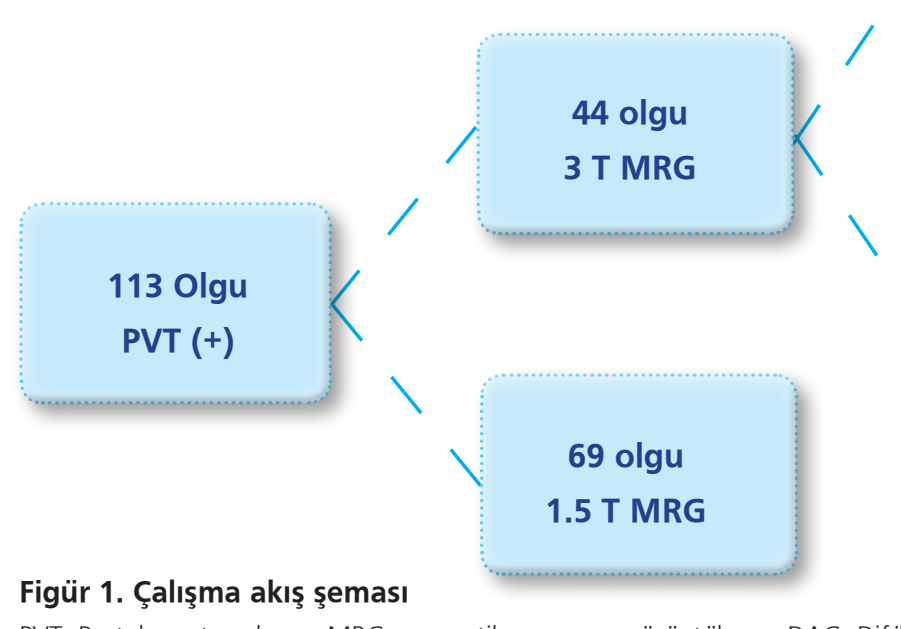

PVT: Portal ven trombozu; MRG: manyetik rezonans görüntüleme; DAG: Difüzyon ağırlıklı görüntüleme. incelemesindeki artefaktlar nedeniyle değerlendirme için uygun olmadığından çalışma dışı bırakıldı. Figür 1 çalışma akış şemasını özetlemektedir. Malign PVT tanısı alan 23 olgu [19 erkek, 4 kadın; ortanca yaş 63 (52-83)] ve benign PVT bulgusu olan 14 olgu [5 erkek, 9 kadın; ortanca yaş 65 (47-82)] tespit edildi. Malign PVT saptanan 16 olguda (\%69.6) eşlik eden HSK mevcuttu. Benign PVT tansı alan 9 olguda (\%64.3) ise altta yatan kronik parankimal karaciğer hastalığı bulguları izlendi (Tablo 1).

\begin{tabular}{|c|c|c|}
\hline & $\begin{array}{c}\text { Malign PVT } \\
\quad(n=23)\end{array}$ & $\begin{array}{c}\text { Benign PVT } \\
\quad(n=14)\end{array}$ \\
\hline Yaş * & $63(52-83)$ & $65(47-82)$ \\
\hline \multicolumn{3}{|l|}{ Cinsiyet } \\
\hline Kadın & $4(\% 17.3)$ & $9(\% 64.3)$ \\
\hline Erkek & $19(\% 82.6)$ & $5(\% 35.7)$ \\
\hline \multicolumn{3}{|l|}{ Etiyoloji } \\
\hline HSK & $16(\% 69.6)$ & $1(\% 7.1)$ \\
\hline Kolanjyiokarsinom & $5(\% 21.7)$ & 0 \\
\hline Safra kesesi kanseri & $1(\% 4.3)$ & 0 \\
\hline Mide kanseri & $1(\% 4.3)$ & 0 \\
\hline Pankreas kanseri & 0 & $2(\% 14.2)$ \\
\hline Siroz & $12(\% 52.2)$ & $9(\% 64.3)$ \\
\hline Kolanjit & 0 & $1(\% 7.1)$ \\
\hline Abdominal cerrahi öyküsü & 0 & $1(\% 7.1)$ \\
\hline
\end{tabular}

* Ortanca (minimum-maksimum), PVT: Portal ven trombozu, HSK: Hepatosellüler kanser.

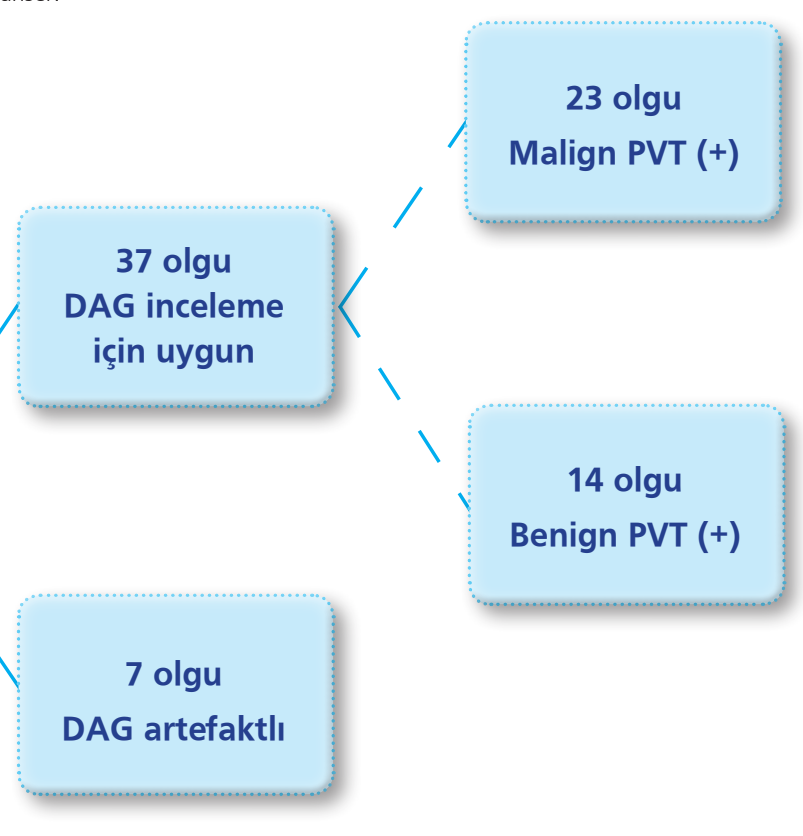




\section{Görüntüleme Bulguları}

Malign PVT saptanan 10 (\%43.5) olguda ana portal ven, 15 (\%65.2) olguda sağ portal ven dalı ve 8 (\%34.8) olguda sol portal ven dalı tutulumu mevcuttu (Resim 1). Benign PVT bulguları mevcut 11 (\%78.6) olguda ise ana portal ven, 5 (\%35.7) olguda sağ portal ven dalı ve 7 (\%50) olguda sol portal ven dalında tromboz saptandı.

Malign ile benign PVT olguları arasında portal ven çapı ölçümleri göz önüne alındığında istatistiksel olarak anlamlı fark saptanmadı ( $p>0.05$ ). Difüzyon ağırlıklı görüntüler PVT sinyal intensitesi yönünden incelendiğinde, malign PVT saptanan 20 (\%86.9) olguda tromboz yüksek sinyal intensitesinde iken benign PVT mevcut 2 (\%14.3) olguda yüksek sinyal intensitesi tespit edildi. Malign ile benign PVT gruplarının karşılaştırılmasında DAG sinyal intensiteleri yönünden anlamlı fark bulundu ( $p<0.001$ ) (Tablo 2).

Her iki gözlemci tarafından yapılan ölçümlerde malign PVT olgularının ortalama ADC değeri benign PVT olgularının ortalama ADC değerinden daha düşük bulundu ( $p$ $<0.001)$. ADC ölçümleri yönünden her iki gözlemci arasında güvenirlik yüksek olarak saptandı $\left(R_{1}: 0.948\right)$ (Tablo 3). Abdomen radyolojisi uzmanı olan gözlemci 1 tarafından yapılan ADC ölçümleri değerlendirildiğinde ise malign

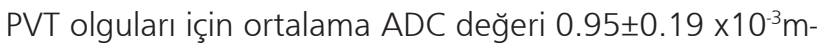
$\mathrm{m}^{2} / \mathrm{s}$ ve benign PVT olguları için ortalama ADC değeri $1.79 \pm 0.26 \times 10^{-3} \mathrm{~mm}^{2} / \mathrm{s}$ olarak ölçüldü. ADC değeri $\leq 1.4 \mathrm{x}$
$10^{-3} \mathrm{~mm}^{2} / \mathrm{s}$ olduğunda ise malign PVT tanısında duyarlılık \%100 ve özgüllük \%100 olarak saptandı.

\section{TARTIŞMA}

Malign ve benign PVT ayrımının yapılması tedavi seçeneklerinin belirlenmesi ve prognozun öngörülmesi açısından büyük önem taşımaktadır $(6,25)$. Portal ven trombozunun karakterizasyonunda histopatolojik inceleme altın standart olmakla birlikte görüntüleme bulguları ile tanı invaziv işlemlerin yerini almıştır. Doppler ultrasonografi, kontrastlı BT ve kontrastlı MRG malign ve benign PVT ayrımında kullanılabilen görüntüleme modaliteleridir. Kontrastlı BT veya MRG incelemelerinde trombüs içi neovaskülarizasyona bağlı trombüste kontrastlanma artışının saptanması malign PVT tanısı için önemli bir bulgudur $(16,24,26)$. Ancak bazı hastalarda böbrek fonksiyon bozukluğuna veya kontrast madde alerjisine bağlı kontrast madde kullanılamamaktadır (27).

Difüzyon ağırlıklı görüntüleme dokudaki su moleküllerinin mikroskobik difüzyonunun ölçümünü temel alan bir görüntüleme yöntemidir. Malign karakterli lezyonda su molekül difüzyonunun kısıtlanması nedeniyle ADC değerleri benign karakterli lezyon ile karşılaştırıldığında daha düşük izlenmektedir. Ayrıca DAG kontrast madde kullanımını gerektirmediğinden kontrast madde kullanımı kontrendike olan olgularda da uygulanabilmektedir $(8,20)$.

\section{Tablo 2. Malign ve benign portal ven trombozunun görüntüleme bulguları}

\begin{tabular}{|c|c|c|c|}
\hline & $\begin{array}{l}\text { Malign PVT } \\
\qquad(n=23)\end{array}$ & $\begin{array}{l}\text { Benign PVT } \\
\quad(n=14)\end{array}$ & $p$ \\
\hline \multicolumn{4}{|c|}{ Portal ven çapı (mm) } \\
\hline Ana portal ven & $16 \pm 5.4$ & $16.3 \pm 4.4$ & 0.519 \\
\hline Sağ portal ven & $14.8 \pm 4.5$ & $12.7 \pm 4.5$ & 0.219 \\
\hline Sol portal ven & $12.8 \pm 4$ & $12.7 \pm 5$ & 0.850 \\
\hline \multicolumn{4}{|c|}{ DAG'de PVT sinyal intensitesi } \\
\hline İzointens & $3(\% 13)$ & $12(\% 85.7)$ & \multirow{3}{*}{$<0.001$} \\
\hline Hipointens & 0 & 0 & \\
\hline Hiperintens & $20(\% 86.9)$ & $2(\% 14.3)$ & \\
\hline
\end{tabular}

PVT: Portal ven trombozu, DAG: Difüzyon ağırlıklı görüntüleme.

Tablo 3. Malign ve benign portal ven trombozunun ADC değerlerinin karşılaştırılması

\begin{tabular}{|c|c|c|c|c|c|c|}
\hline \multicolumn{4}{|c|}{$A D C\left(\times 10^{-3} \mathrm{~mm}^{2} / \mathrm{s}\right)$} & \multirow{2}{*}{$\begin{array}{c}\text { Sınıf İçi } \\
\text { Korelasyon }\end{array}$} & \multicolumn{2}{|c|}{ \%95 Güven Aralığı } \\
\hline & Malign PVT & Benign PVT & p & & Alt Sınır & Üst Sınır \\
\hline Gözlemci 1 & $0.95 \pm 0.19$ & $1.79 \pm 0.26$ & $<0.001$ & \multirow{2}{*}{0.948} & \multirow{2}{*}{0.900} & \multirow{2}{*}{0.973} \\
\hline Gözlemci 2 & $1.02 \pm 0.28$ & $1.87 \pm 0.26$ & $<0.001$ & & & \\
\hline
\end{tabular}



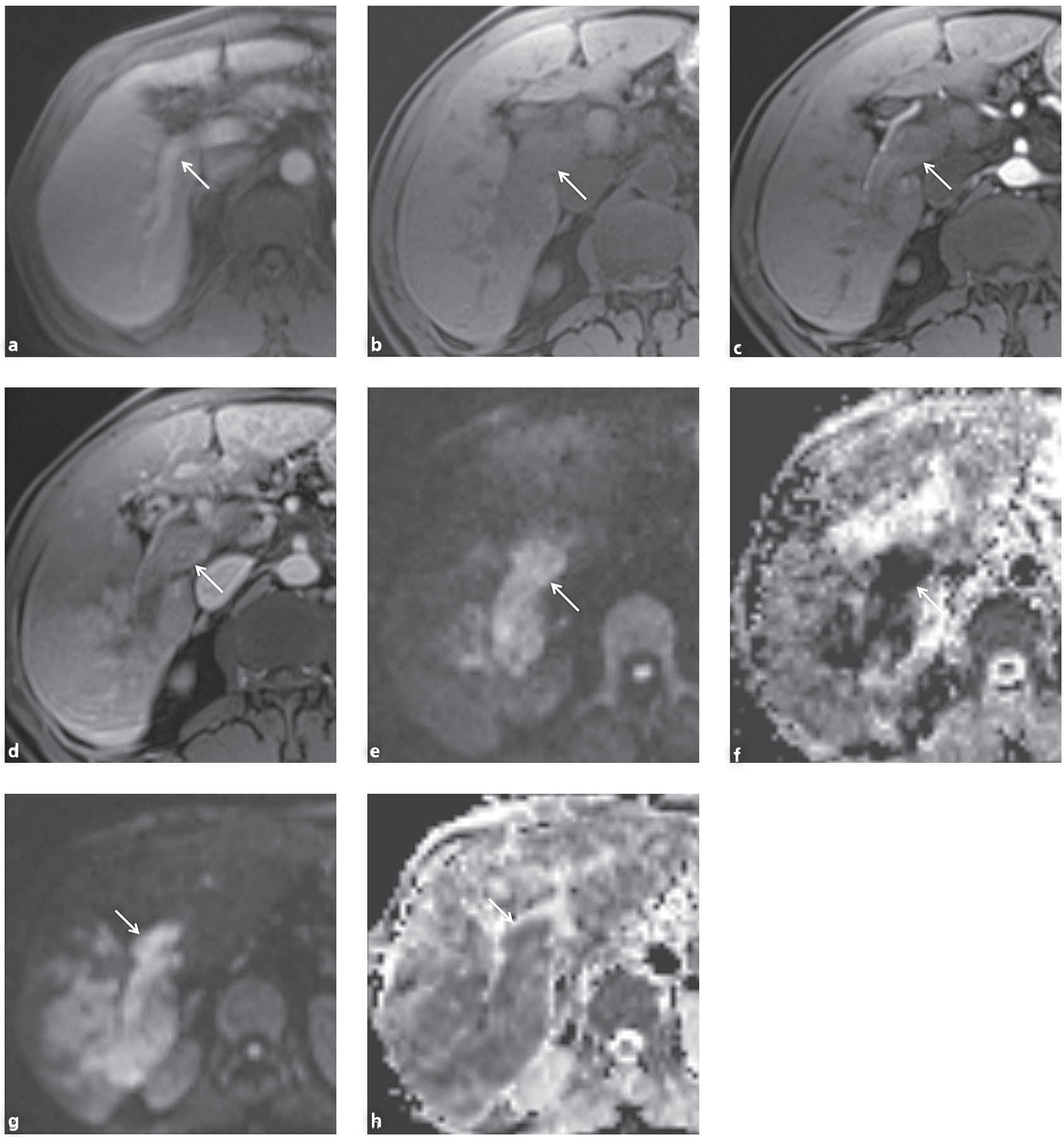

Resim 1. 54 yaşında, kronik hepatit B enfeksiyonu nedeniyle takipli erkek hasta. Kontrastlı aksiyel T1-ağırlıklı görüntüde (a) sağ portal ven dalında akım patenttir (ok). 6 ay sonra elde edilmiş prekontrast aksiyel T1-ağırlıklı görüntüde (b) sağ portal ven dalının çapının artış gösterdiği anlaşıımıştır (ok). Arteriyel faz kontrastlı aksiyel T1-ağırlıklı görüntüde (c) portal ven trombozu izlenmiş olup prekontrast görüntüler ile karşılaştırıldığında $\geq \% 15$ kontrast tutulumu göstermesi nedeniyle malign portal ven trombozu olarak değerlendirilmiştir (ok). Portal venöz faz kontrastlı aksiyel T1-ağırlıklı görüntüde (d) malign portal ven trombozu (ok) ve karaciğer sağ lobda parankimal perfüzyon değişiklikleri izlenmiş̧tir. Difüzyon ağırlıklı görüntülemede ( $b=800 \mathrm{~s} / \mathbf{m m 2}$ ) (e) malign portal ven trombozu yüksek sinyal intensitesindedir (ok). Karaciğer sağ lobda portal ven trombozu komşuluğunda infiltratif tipte hepatosellüler karsinom lehine değerlendirilen yüksek sinyal intensitesinde düzensiz sınırlı lezyonlar izlenmiştir. ADC haritasında (f) malign portal ven trombozu difüzyon kısıtlaması göstermektedir. 6 ay sonra elde edilmiş difüzyon ağırlıklı görüntülemede (b=800 s/mm2) (g) sağ portal ven dalında yüksek sinyal intensitesinde malign portal ven trombozu (ok) ile çevresinde interval dönemde progresyon göstermiş infiltratif hepatosellüler karsinom izlenmiştir. ADC haritasında ( $h$ ) malign portal ven trombozunda (ok) ve hepatosellüler karsinomda difüzyon kısıtlanması izlenmiştir. 
Çalışmamızda malign ve benign PVT ayrımında $3 T$ $M R G$ 'de DAG ile ADC değerlerinin tanıya katkı sağladığı saptanmışıtır. Malign ile benign PVT arasında DAG'de sinyal intensitelerinde anlamlı fark bulunmuştur $(p<0.001)$. Her iki gözlemci tarafından yapılan ölçümlerde malign PVT olgularının ADC değerleri benign PVT olgularının $A D C$ değerlerinden daha düşük olarak saptanmıştır ( $p$ $<0.001)$. Catalano ve ark.nın yaptığı HSK olgularında malign ile benign PVT ayrımını araştıran çalışmada, malign PVT için ortalama ADC değeri $0.88 \times 10-3 \mathrm{~mm} 2 / \mathrm{s}$, benign PVT için ortalama ADC değeri ise $2.89 \times 10^{-3} \mathrm{~mm}^{2} / \mathrm{s}$ olarak bildirilmiştir (8). Bu çalışmada $\mathrm{DAG}^{\prime}$ de trombozun HSK ile benzer sinyal intensitesi göstermesi ve ADC değerleri ile malign ve benign PVT ayrımının yapılabileceği öngörülmüştür (8). 1.5T MRG sistemi kullanılarak yapılan, 18 benign PVT ile 49 malign $\mathrm{PVT}^{\prime}$ yi inceleyen diğer bir çalışmada ise benign PVT için ortalama ADC değeri $1.00 \pm 0.39 \times 10^{-3} \mathrm{~mm}^{2} / \mathrm{s}$, malign PVT için ortalama ADC değeri $0.92 \pm 0.25 \times 10^{-3} \mathrm{~mm}^{2} / \mathrm{s}$ olarak ölçülmüştür (26). Bu çalışmada benign ile malign PVT ADC değerleri arasında istatistiksel olarak anlamlı fark saptanmamıştır (26). Sandrasegaran ve ark.nın yaptığı çalışmada, 16 malign PVT ve 10 benign PVT olgusunun 1.5T MRG ünitesinde elde edilmiş $A D C$ değerlerinin karşılaştırılmasında istatistiksel olarak anlamlı fark bulunmamışıı (12). 1.5T MRG ünitesinin kullanıldığı, 18 malign PVT ve 10 benign PVT olgusunun değerlendirildiği bir araştırmada ise malign PVT $A D C$ değerleri benign PVT ADC değerlerinden istatistiksel

\section{KAYNAKLAR}

1. Okuda K, Ohnishi K, Kimura K, et al. Incidence of portal vein thrombosis in liver cirrhosis. An angiographic study in 708 patients. Gastroenterology 1985;89:279-86.

2. Demirci H, Öztürk K, Uygun A. Portal Vein Thrombosis. J Clin Anal Med 2015;6(Suppl 4):587-9.

3. Inan M, Sarıoğlu T, Serhat TH. Portomesenteric venous thrombosis as a rare cause of acute abdomen in a young patient: What should be the process of diagnosis and management?. Ulus Cerrahi Derg 2013;29:84-7.

4. Tavusbay C, Kamer E, Acar T, et al. Portal vein thrombosis as a rare cause of abdominal pain: When to consider? Turk J Surg 2017;33:126-9

5. Sotiropoulos GC, Radtke A, Schmitz KJ, et al. Liver transplantation in the setting of hepatocellular carcinoma and portal vein thrombosis: a challenging dilemma? Dig Dis Sci 2008;53:1994-9.

6. Takizawa D, Kakizaki S, Sohara N, et al. Hepatocellular carcinoma with portal vein tumor thrombosis: clinical characteristics, prognosis, and patient survival analysis. Dig Dis Sci 2007;52:3290-5.

7. Sakata J, Shirai Y, Wakai T, et al. Preoperative predictors of vascular invasion in hepatocellular carcinoma. Eur J Surg Oncol 2008;34:900-5.

8. Catalano OA, Choy G, Zhu A, Hahn PF, Sahani DV. Differentiation of malignant thrombus from bland thrombus of the portal vein in patients with hepatocellular carcinoma: application of diffusion-weighted MR imaging. Radiology 2010;254:154-62. olarak anlamlı düşük saptanmıştır (23). Çalışmalarda elde edilmiş farklı sonuçların nedeni tam olarak aydınlatılamamış olsa da Ahn ve ark.nın yaptığı çalışmada benign PVT olgularında saptanan düşük $A D C$ değerlerinin trombozun evresine bağlı olabileceği ileri sürülmüştür (26).

Damar çapının artışı malign PVT tanısı için bir görüntüleme bulgusu olarak bildirilmiştir $(15,24)$. Çalışmamızda ise malign ve benign PVT olguları karşılaştııılı̆ğında tutulan damar çapı yönünden istatistiksel anlamlı fark saptanmamıştır. Damar ekspansiyonu hem malign hem benign PVT olgularında akut dönemde görülebileceği için PVT ayrımı için güvenilir bir bulgu olmadığı düşünülmüştür (26).

Çalışmamızın bazı sınırlııkları mevcuttur. Çalışmamız retrospektif özellikte olup olgu sayısı kısıtıdır. Malign ile benign PVT ayrımında histopatolojik tanı olmaması da diğer bir limitasyondur. Çalışmamızın sonuçlarının doğrulanması için prospektif olarak planlanan araştırmalara ihtiyaç vardır.

Sonuç olarak 3T MRG'de DAG malign ile benign PVT ayrımı için tanıya katkı sağlamaktadır. Portal ven trombozunun DAG'deki sinyal intensitesi ve ADC değerleri ile karakterizasyonunun yapılabilmesi özellikle kontrast madde kullanımının uygun olmadığı olgularda önem taşımaktadır.

\section{"Tüm yazarlar herhangi bir çıkar çatışması olmadığı- nı beyan ederler."}

9. Harding DJ, Perera MT, Chen F, Olliff S, Tripathi D. Portal vein thrombosis in cirrhosis: Controversies and latest developments. World J Gastroenterol 2015;21:6769-84.

10. Fujiyama S, Saitoh $S$, Kawamura $Y$, et al. Portal vein thrombosis in liver cirrhosis: incidence, management, and outcome. BMC Gastroenterol 2017;17:112

11. Cohen J, Edelman RR, Chopra S. Portal vein thrombosis: a review. Am J Med 1992;92:173-82.

12. Sandrasegaran K, Tahir B, Nutakki K, et al. Usefulness of conventional MRI sequences and diffusion-weighted imaging in differentiating malignant from benign portal vein thrombus in cirrhotic patients. AJR Am J Roentgenol 2013;201:1211-9.

13. Tarantino L, Francica G, Sordelli I, et al. Diagnosis of benign and malignant portal vein thrombosis in cirrhotic patients with hepatocellular carcinoma: color Doppler US, contrast-enhanced US, and fine-needle biopsy. Abdom Imaging 2006;31:537-44.

14. Gawande $R$, Jalaeian $H$, Niendorf $E$, et al. MRI in differentiating malignant versus benign portal vein thrombosis in patients with hepatocellular carcinoma: Value of post contrast imaging with subtraction. Eur J Radiol 2019;118:88-95.

15. Tublin ME, Dodd GD 3rd, Baron RL. Benign and malignant portal vein thrombosis: differentiation by CT characteristics. AJR Am J Roentgenol 1997;168:719-23.

16. Elmas N, Harman M. Karaciğerin vasküler hastalıkları. Trd Sem 2015;3:394-405. 
17. Battal $B$, Kocaoglu M, Akgun V, et al. Diffusion-weighted imaging in the characterization of focal liver lesions: efficacy of visual assessment. J Comput Assist Tomogr 2011;35:326-31.

18. Xu PJ, Yan FH, Wang JH, et al. Contribution of diffusion-weighted magnetic resonance imaging in the characterization of hepatocellular carcinomas and dysplastic nodules in cirrhotic liver. J Comput Assist Tomogr 2010;34:506-12.

19. Miller FH, Hammond N, Siddiqi AJ, et al. Utility of diffusion-weighted MRI in distinguishing benign and malignant hepatic lesions. J Magn Reson Imaging 2010;32:138-47.

20. Taouli B, Koh DM. Diffusion-weighted MR imaging of the liver. Radiology 2010;254:47-66.

21. Sandrasegaran K, Akisik FM, Lin C, et al. The value of diffusion-weighted imaging in characterizing focal liver masses. Acad Radiol 2009;16:1208-14.

22. Parikh T, Drew SJ, Lee VS, et al. Focal liver lesion detection and characterization with diffusion-weighted MR imaging: comparison with standard breath-hold T2-weighted imaging. Radiology 2008;246:812-22
23. Aumann EK, Server S, Koyuncu Sokmen B, et al. Diagnostic performances of intravoxel incoherent motion and conventional diffusion-weighted imaging in the differential diagnosis of benign and malignant portal vein thrombus. Abdom Radiol (NY) 2018;43:2270-6.

24. Shah ZK, McKernan MG, Hahn PF, Sahani DV. Enhancing and expansile portal vein thrombosis: value in the diagnosis of hepatocellular carcinoma in patients with multiple hepatic lesions. AJR Am J Roentgenol 2007;188:1320-3.

25. Connolly GC, Chen R, Hyrien O, et al. Incidence, risk factors and consequences of portal vein and systemic thromboses in hepatocellular carcinoma. Thromb Res 2008;122:299-306.

26. Ahn JH, Yu JS, Cho ES, et al. Diffusion-weighted MRI of malignant versus benign portal vein thrombosis. Korean J Radiol 2016;17:533-40.

27. Peak AS, Sheller A. Risk factors for developing gadolinium-induced nephrogenic systemic fibrosis. Ann Pharmacother 2007;41:1481-5. 